\title{
Promoter methylation of RASSF1A modulates the effect of the microtubule-targeting agent docetaxel in breast cancer
}

\author{
EUN YOUNG GIL ${ }^{1,5}$, UK HYUN JO ${ }^{1}$, HOISEON JEONG ${ }^{2}$, YOUNG MI WHANG ${ }^{1}$, OK HEE WOO ${ }^{3}$, \\ KYU RAN CHO ${ }^{3}$, JAE HONG SEO ${ }^{1}$, AEREE KIM ${ }^{2}$, EUN SOOK LEE ${ }^{4}$, INSONG KOH ${ }^{6}$, \\ YEUL HONG KIM $^{1}$ and KYONG HWA PARK ${ }^{1}$ \\ Division of Oncology/Hematology, Departments of ${ }^{1}$ Internal Medicine, ${ }^{2}$ Pathology, ${ }^{3}$ Radiology and ${ }^{4}$ Surgery; \\ ${ }^{5}$ Graduate School of Medicine, Korea University College of Medicine; ${ }^{6}$ Department of Physiology, \\ College of Medicine, Hanyang University, Seoul, Republic of Korea
}

Received February 7, 2012; Accepted April 12, 2012

DOI: $10.3892 /$ ijo.2012.1470

\begin{abstract}
Docetaxel is one of the most commonly used chemotherapeutic agents in breast cancer. To avert from significant toxicities with no clinical benefit, identification of predictive markers for response is one of the most important unsolved clinical needs. Therefore, the potential associations of RASSF1A hypermethylation and response to docetaxel-based chemotherapy were evaluated, and the underlying mechanism was studied. The expression of RASSF1A in breast cancer cell lines and tissues of normal breast, ductal carcinoma in situ (DCIS), and breast cancer $(n=45)$ was analyzed by immunohistochemistry and western blot analysis. Immunohistochemical staining showed that the expression of RASSF1A was frequently lost in primary breast cancers and human breast cancer cell lines, while normal breast tissues or DCIS displayed moderate to strong expression. Furthermore, quantitative methylation analysis of the RASSF1A promoter region in 45 primary breast cancers revealed that $R A S S F 1 A$ was frequently methylated in primary breast cancers $(\geq 20 \%$ methylation in $53 \%$ of the patients), and prospective analysis in patients with locally advanced or recurrent breast cancer showed that the mean level of methylation of RASSF1A was significantly higher in patients who did not respond to docetaxel-based chemotherapy $(30.6 \pm 8.5 \%)$ than patients with partial or complete response $(20.1 \pm 11.2 \%, p=0.042)$. Finally, in vitro studies showed that RASSF1A had cooperative activity in suppression of cancer cell growth and proliferation by enhancing docetaxel-induced cell cycle arrest. Our results suggest that hypermethylated RASSF1A
\end{abstract}

Correspondence to: Professor Kyong Hwa Park, Division of Oncology/Hematology, Department of Internal Medicine, Korea University Anam Hospital, Korea University College of Medicine, 126-1 Anam-Dong 5-Ga, Seongbuk-Gu, Seoul 136-705, Republic of Korea

E-mail: khpark@korea.ac.kr

Key words: RASSF1A, docetaxel, methylation, cyclin B1, breast cancer is an important modulating factor for the efficacy of docetaxelbased chemotherapy in breast cancer.

\section{Introduction}

Breast cancer is one the most common cancers in women worldwide as well as in Korea (1). Although treatment outcome of breast cancer has been greatly improved due to early diagnosis and development of various targeted agents, prognosis of patients with locally advanced breast cancer still remains to be improved. Recently, neoadjuvant chemotherapy has increasingly been considered, since the chance for breast conservation is significantly increased and the treatment outcome was similar to that in patients who received adjuvant chemotherapy after primary surgery $(2,3)$. Therefore, it is critical to identify biologic markers for response to commonly used chemotherapeutic agents in a neoadjuvant setting. To date, several studies have been conducted for the identification of the predictive markers for response to neoadjuvant chemotherapy, and some biologic characteristics of tumors such as hormone receptor status, HER-2 overexpression, and Ki-67 labeling index have been suggested as potential biomarkers $(4,5)$. However, none of these has been proposed as a marker based on the biologically relevant mechanisms in their cytotoxicity for a specific chemotherapeutic agent. Thus, the multi-factorial molecular mechanisms determining chemotherapy response remain largely unclear.

Taxanes, including docetaxel, in combination with other cyctotoxic agents or targeted agents are the standard treatment for locally advanced or metastatic breast cancers. Many clinical trials have demonstrated the efficacy of the taxanes in this group of patients, however, about $20 \%$ of breast cancers do not shrink significantly or progress with neoadjuvant treatment and $30-40 \%$ of the patients who had residual disease ultimately get recurrent cancer $(2,3)$. Therefore, identification of promising biomarker which can guide physicians to select best treatment regimen is clearly unmet need in this era of personalized care.

In breast cancers, multitudes of genes are known to be suppressed by epigenetic mechanisms in the promoter region, and RASSF $1 A$ is one of the most frequently silenced genes in this type of cancer (6). Moreover, inactivation of the RASSF1A 
gene by the methylation is known as an early event in the carcinogenesis of breast cancer (7-9), and recent studies have suggested detection of methylated RASSF1A in serum or body fluids as a biomarker for early breast cancer development (9-11). Furthermore, there is a growing amount of data, demonstrating that methylation status in the promoter region of RASSF1A is associated with poor prognosis in breast cancer patients (12-14) as well as patients with other cancers (15-18). Epigenetic or genetic modification of RASSF1A gene may have effects on key biological processes including apoptosis, cell cycle regulation, mitosis, and microtubule dynamics in cancer cells, which have been shown in numerous studies (19-22). Our recent data showed that RASSF1A protein enhances microtubule-targeted drugs in inducing $\mathrm{G} 2 / \mathrm{M}$ arrest in non-small cell lung carcinoma (NSCLC) cells (23), implicating RASSF1A in cytotoxicity of anti-mitotic drugs. However, only a few studies have thus far been focused on the biologic consequence of the methylation of RASSF1A in various cancer types $(24,25)$, but not in breast cancer. Therefore, we hypothesized that commonly-silenced RASSF1A in breast cancer can modulate the response to the frequently used cytotoxic agent, docetaxel.

To this end, we prospectively investigated the relationship between the methylation level of RASSF1A gene and response to docetaxel-based chemotherapy in patients with locally advanced or recurrent breast cancer using methylation-specific pyrosequencing analysis, and found that the mean level of methylation in the promoter region of RASSF1A showed a significant association with response to docetaxel-based chemotherapy. Further in vitro study showed that RASSF1A had cooperative activity in suppression of cancer cell growth and proliferation by enhancing docetaxel-induced cell cycle arrest.

\section{Materials and methods}

Cell culture and transfection. Three human breast cancer cell lines, ZR-75-1, MDA-MB-231, and MCF-7 cells, were obtained from the Korean Cell Line Bank (Seoul, Korea). For transfection, cells were transiently transfected with $1 \mu \mathrm{g}$ of RASSF1A DNA (kindly provided by Dr S. Tommasi of the Beckman Research Institute, Duarte, CA, USA) or the empty pcDNA 3.1 plasmid using the Lipofectamine reagent (Invitrogen, Carlsbad, CA, USA). To generate cells stably expressing RASSF1A, cells were transfected and selected in geneticin (G418) (Life Technologies Inc., Grand Island, NY, USA). Only low passage cells (passage $<10$ ) were used for experiments.

Patients and tissues. A total of 45 primary breast cancer tissues were obtained from newly diagnosed breast cancer patients who were scheduled to receive docetaxel-based chemotherapy for locally advanced or metastatic disease. Ten non-cancer tissues were obtained from 5 patients with DCIS and 5 normal breast tissues from reduction mammoplasty. All patients gave their informed consent, and the study was approved by the Ethics and Scientific Committees of our Institution (no. 2008-267). Tissues were processed and stored as frozen block at $-80^{\circ} \mathrm{C}$ or paraffinembedded block in Korea Lung Tissue Bank (Seoul, Korea) until analysis. Clinicopathological data involving age, TNM stage, tumor grade, ER/PR/HER-2 expression status, and response to docetaxel-based chemotherapy were collected. Responders in this study were defined as the patients who achieved a partial or complete response to chemotherapy, according to the RECIST criteria version 1.1 (26).

Cell proliferation assays. Cell proliferation was assessed by both colorimetric MTT assay and $\left[{ }^{3} \mathrm{H}\right]$-thymidine incorporation. Thus, each breast cancer cell line was incubated with docetaxel for $48 \mathrm{~h}$ after $24 \mathrm{~h}$ of serum starvation. For the MTT assay, the cells were incubated for $4 \mathrm{~h}$ with MTT reagent and then lysed in $50 \%$ dimethylformamide (DMSO) and $20 \%$ SDS-PAGE at $37^{\circ} \mathrm{C}$. Optical densities (OD) at 550 and $670 \mathrm{~nm}$ were measured using a plate reader (BioRad, Hercules, CA, USA), and differential OD between 550 and $670 \mathrm{~nm}$ (OD 550-670 nm) was determined. For $\left[{ }^{3} \mathrm{H}\right]$-thymidine incorporation assay, $1 \mu \mathrm{l}$ of $\left[{ }^{3} \mathrm{H}\right]$-thymidine (Amersham, Buckinghamshire, UK) was added per well and plates were incubated for $18 \mathrm{~h}$. Then, cells were harvested in a cell harvester, and radioactivity (dpm) was counted using a $\beta$-counter. The results were expressed as $\mathrm{dpm} / \mathrm{mg}$ protein or as percentage of the control (defined as 100\%).

Methylation-specific PCR (MSP) analysis. Genomic DNA was extracted from control, 5-aza-deoxycytidine-treated $(10 \mu \mathrm{M}$ for 3 days) cells using QIAamp ${ }^{\circledR}$ DNA Blood Mini Kit (Qiagen, Valencia, CA, USA), by following the manufacturer's instructions. Bisulfite modification of DNA $(1 \mu \mathrm{g})$ was performed using the EZ DNA Methylation-Gold kit ${ }^{\mathrm{TM}}$ (Zymo Research, Orange, CA, USA). Based on the promoter sequence of RASSF1A, methylation- and unmethylation-specific primers were designed using Serologicals CpGware software (http://apps.serologicals. com/CPGWARE/dna_form2.html) methylated, 5'-GCTAAC AAACGCGAACCG-3'; 5'-GGGTTTTGCGAGAGCGCG-3' and unmethylated, 5'-CACTAACAAACACAAAC CAAAC-3'; 5'-GGTTTTGTGAGAGTGTGTTTAG-3'; product sizes 169 and 169 bp, respectively (PMID: 11333291). Bisulfite-modified DNA ( $2 \mu \mathrm{l}$ out of $10 \mu \mathrm{l}$ elute) was used for each PCR. All experiments were performed in triplicate and repeated at least three times.

Quantitation of RASSF1A promoter methylation by pyrosequencing. Bisulfite-treated DNA from tumors was used for PCR amplifications. Pyrosequencing was performed using the PSQ96ID system (Qiagen) including PyroMark Gold Q96 reagents. Primers were designed by the PyroMark Assay design 2.0 (Qiagen). The primers amplify a stretch of the RASSF1A exon 1 (Ensemble ID: ENST00000266020). The primers target $\mathrm{CpG}$ regions within this stretch. PCR was carried out using $2 \mu \mathrm{l}$ bisulfite-treated DNA under the following conditions: $94^{\circ} \mathrm{C}$ for $5 \mathrm{~min}, 45 \mathrm{x}\left(94^{\circ} \mathrm{C}\right.$ for $30 \mathrm{sec}, 55^{\circ} \mathrm{C}$ for $30 \mathrm{sec}, 72^{\circ} \mathrm{C}$ for $\left.30 \mathrm{sec}\right)$, $72^{\circ} \mathrm{C}$ for $5 \mathrm{~min}$. Intactness of the PCR product was assessed by electro-phoresis on $2 \%$ agarose gel (Seakem ${ }^{\circledR}$ LE Agarose, Lonza) and subsequent ethidium bromide staining. The pyrosequencing primers target a 46-nt segment, which lies within the previously amplified stretch of RASSF1A exon 1 and contains 7 CpGs(GTCGGGGTTEGTTTTGTGGTTTEGTTEGG TTCGCGTTTGTTAGCGT).

Immunohistochemistry and immunofluorescence. Expression of RASSF1A protein in tissue samples and breast cancer cell lines were determined with anti-RASSF1A monoclonal antibody (clone eB114, eBioscience, Minneapolis, MI, USA) as previously described (27). The staining results were evaluated according to 
the immunodetection of stain intensity and amounts of positive cells by two pathologists (A.K. and H.J.), who discussed each case until they reached a consensus. The degree of staining was subdivided as follows: the stain intensity could be from 0 to 3 ( 0 , no staining; 1 , focal or fine granular, weak staining; 2 , linear or cluster, strong staining; and 3 , diffuse, intense staining); and the positive cells in the observed breast tissue samples ranged from 0 to 3 in percentage ( 0 , no staining; $1,<30 \% ; 2,30-70 \%$; and $3,>70 \%)$. The samples were scored by their summation: 0-1 (-); 2-3 (+); 4 (++); 5-6 (+++). Any staining score 2 or above $(+)$ was considered as positive expression.

For immunofluorescence, cells were plated on $18 \mathrm{~mm}$ coverslips and treated on the next day with $10 \mu \mathrm{M}$ 5-aza-deoxycytidine (Sigma Co., St. Louis, MO, USA). After 48-h treatment, cells were fixed with $4 \%$ paraformaldehyde, permeabilized in $0.25 \%$ Triton X-100 in PBS, and blocked in PBS/5\% BSA. RASSF1A was detected using anti-RASSF1A (eBioscience) followed by incubation with fluorescent conjugated secondary antibodies (Molecular Probes, Eugene, OR, USA). After washing, cells were counterstained with 4',6-diamidino-2-phenylindole (DAPI) (Sigma Co.), mounted on glass slides, and examined by a DP40 (Olympus, Tokyo, Japan).

Western blot analysis. The expressions of proteins were detected using relevant antibodies (anti-RASSF1A, Cdk1, Cdk2, Cdk4, cyclin B, Cell Signaling, Boston, MA, USA; anti-cyclin D1, Calbiochem, San Diego, CA, USA; anti-p21, Santa Cruz Biotechnology, Santa Cruz, CA, USA). The collected cells were lysed with $10 \mu \mathrm{l}$ of dilution buffer containing $20 \mathrm{mM} 3$-morpholinopropanesulfonic acid ( $\mathrm{pH} 7.2), 25 \mathrm{mM} \beta$-glycerophosphate, $5 \mathrm{mM}$ EDTA, $1 \mathrm{mM}$ sodium orthovanadate, $1 \mathrm{mM}$ dithiothreitol, and protease inhibitors $(100 \mu \mathrm{g} / \mathrm{ml}$ phenylmethylsulfonyl fluoride, $1 \mu \mathrm{g} / \mathrm{ml}$ aprotinin, and $1 \mu \mathrm{g} / \mathrm{ml}$ leupeptin). The total

A

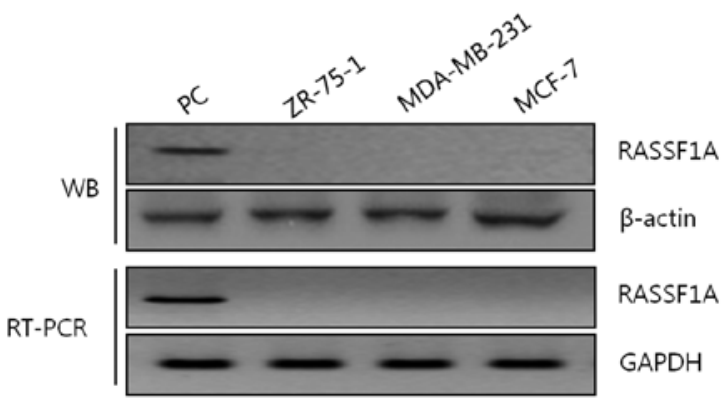

cell lysates were resolved on $8-12 \%$ SDS-PAGE as previously described (23).

Cell cycle analysis. The cell cycle distribution was determined by flow cytometric analysis of propidium iodide (PI) labeled cells. Thus, cells were seeded at $1 \times 10^{5}$ cells $/ 60-\mathrm{mm}$ plate and treated with docetaxel. The cells were harvested, fixed in $70 \%$ ethanol, and then stored at $-20^{\circ} \mathrm{C}$. The cells were then washed twice with ice-cold PBS and incubated with ribonuclease and PI. Cell cycle was analyzed by BD FACScan flow cytometry (Becton Dickinson, Franklin Lakes, NJ, USA) and CellQuest software.

Statistical analysis. Mean methylation level of RASSF1A according to the clinicopathological parameters were analyzed by Student's t-test. A logistic regression model was applied to determine whether a factor was independent predictor of response to chemotherapy in a multivariate analysis. A two-sided 0.05-level test was determined for statistical significance. All data analyses were conducted with SPSS software (SPSS Inc., Chicago, IL, USA).

\section{Results}

RASSF1A protein and mRNA expressions are downregulated in breast cancer cell lines and primary breast cancers. Western blot analysis and RT-PCR revealed the loss of RASSF1A protein and mRNA expression in 3 breast cancer cell lines (ZR-75-1, MDA-MB-231, MCF-7) (Fig. 1A). Next, we evaluated the expression of RASSF1A using immunohistochemical analysis, and Fig. 1B shows that benign breast tissues and DCIS tissues were strongly positive for RASSF1A, whereas invasive ductal carcinoma tissues were negative for RASSF1A staining. Further analysis of primary invasive ductal carcinoma of breast revealed that RASSF1A was lost in $27(60 \%)$ out of 45 primary breast samples (Table I), thus indicating that RASSF1A expression is low or lost in many cases of primary breast cancer specimens as well as selected breast cancer cell lines. These results support earlier hypothesis that the loss of RASSF1A is one of the important events in the breast cancer carcinogenesis $(7,8)$.

RASSF1A promoter is methylated in breast cancer cell lines. Next, we investigated underlying mechanism of downregulation of RASSFIA, and tested whether any epigenetic modification regulates RASSF1A gene expression in breast

B

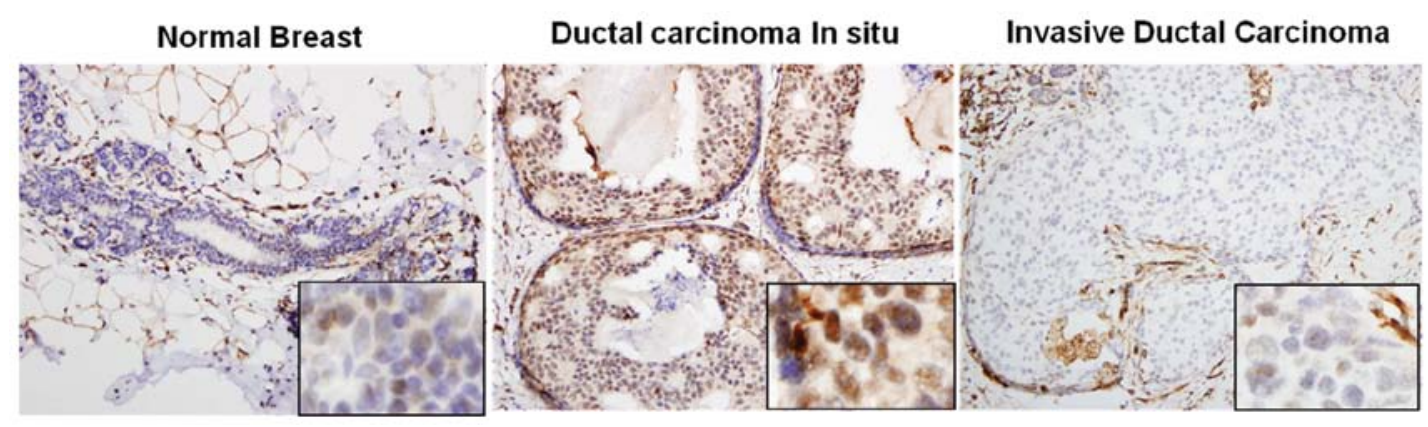

Figure 1. Decreased expression of RASSF1A in breast cancer. (A) Expression of RASSF1A in 3 breast cancer cell lines, determined by western blot analysis and RT-PCR analysis. $\beta$-actin and GAPDH were used as internal controls. (B) RASSF1A protein expression in normal breast, DCIS and invasive ductal carcinoma. Brown staining in immunohistochemistry is indicative of RASSF1A protein expression (magnification x100). 
Table I. Correlation between RASSF1A gene methylation, protein expression, and clinicopathological characteristics of breast cancer patients $(n=45)$.

\begin{tabular}{|c|c|c|c|c|c|c|}
\hline \multirow[b]{2}{*}{$\begin{array}{l}\text { Clinicopathological } \\
\text { characteristics }\end{array}$} & \multicolumn{3}{|c|}{ RASSF1A methylation } & \multicolumn{3}{|c|}{ RASSF1A expression } \\
\hline & $\begin{array}{l}\text { Number of } \\
\text { patients } \\
\text { (no.) }\end{array}$ & $\begin{array}{c}\text { Level of } \\
\text { methylation } \\
(\%, \text { mean } \pm \text { SD })\end{array}$ & $\mathrm{P}$ & $\begin{array}{l}\text { Positive } \\
\text { (no.) }\end{array}$ & $\begin{array}{l}\text { Negative } \\
\text { (no.) }\end{array}$ & $P$ \\
\hline \multicolumn{7}{|l|}{ Age (years) } \\
\hline$<35$ & 4 & $17.7 \pm 18.7$ & \multirow[t]{2}{*}{ NS } & 1 & 3 & \multirow[t]{2}{*}{ NS } \\
\hline$\geq 35$ & 41 & $21.7 \pm 16.6$ & & 17 & 24 & \\
\hline \multicolumn{7}{|l|}{ Menopausal status } \\
\hline Premenopausal & 28 & $18.5 \pm 16.3$ & \multirow[t]{2}{*}{ NS } & 7 & 21 & \multirow[t]{2}{*}{0.013} \\
\hline Postmenopausal & 17 & $27.0 \pm 16.2$ & & 6 & 11 & \\
\hline \multicolumn{7}{|c|}{ Primary tumor size $(\mathrm{cm})$} \\
\hline$<2.0$ & 13 & $16.9 \pm 16.6$ & \multirow[t]{2}{*}{ NS } & 6 & 7 & \multirow[t]{2}{*}{ NS } \\
\hline$\geq 2.0$ & 32 & $23.7 \pm 16.5$ & & 20 & 12 & \\
\hline \multicolumn{7}{|l|}{ Stage } \\
\hline II-III & 30 & $18.7 \pm 14.4$ & \multirow[t]{2}{*}{0.088} & 10 & 20 & \multirow[t]{2}{*}{ NS } \\
\hline $\mathrm{IV}$, recurrent & 15 & $27.7 \pm 16.4$ & & 8 & 7 & \\
\hline \multicolumn{7}{|l|}{ ER } \\
\hline Positive & 19 & $28.2 \pm 17.7$ & \multirow[t]{2}{*}{0.024} & 6 & 13 & \multirow[t]{2}{*}{ NS } \\
\hline Negative & 26 & $17.0 \pm 14.4$ & & 12 & 14 & \\
\hline \multicolumn{7}{|l|}{ PR } \\
\hline Positive & 15 & $29.5 \pm 17.4$ & \multirow[t]{2}{*}{0.026} & 3 & 12 & \multirow[t]{2}{*}{ NS } \\
\hline Negative & 30 & $17.9 \pm 15.1$ & & 15 & 15 & \\
\hline \multicolumn{7}{|l|}{ HER-2 } \\
\hline Positive & 16 & $21.6 \pm 15.6$ & \multirow[t]{2}{*}{ NS } & 9 & 7 & \multirow[t]{2}{*}{ NS } \\
\hline Negative & 29 & $21.8 \pm 17.4$ & & 9 & 20 & \\
\hline \multicolumn{7}{|l|}{ Triple negativity } \\
\hline Yes & 15 & $14.4 \pm 11.9$ & \multirow[t]{2}{*}{0.041} & 5 & 10 & NS \\
\hline No & 30 & $24.8 \pm 17.0$ & & 13 & 17 & \\
\hline Tumor grade & & & & & & \\
\hline G1 & 2 & $2.5 \pm 0.1$ & NS & 0 & 2 & NS \\
\hline G2 & 19 & $21.7 \pm 19.1$ & & 7 & 12 & \\
\hline G3 & 24 & $23.3 \pm 15.4$ & & 11 & 13 & \\
\hline Ki-67 (\%) & & & & & & \\
\hline$\geq 20$ & 35 & $22.0 \pm 17.5$ & NS & 17 & 18 & 0.034 \\
\hline$<20$ & 10 & $21.6 \pm 16.7$ & & 1 & 9 & \\
\hline p53 (\%) & & & & & & \\
\hline$\geq 10$ & 28 & $22.9 \pm 17.1$ & NS & 10 & 18 & NS \\
\hline$<10$ & 17 & $19.8 \pm 16.1$ & & 8 & 9 & \\
\hline Response to chemoth & & & & & & \\
\hline Responders & 32 & $20.1 \pm 11.2$ & 0.042 & 14 & 17 & 0.343 \\
\hline Non-responders & 13 & $30.6 \pm 8.5$ & & 3 & 10 & \\
\hline
\end{tabular}

ER, estrogen receptor; PR, progesterone receptor; HER-2, human epidermal growth factor receptor 2; NS, not statistically significant.

cancer cell lines, as reported previously $(28,29)$. RASSF1A mRNA and protein levels were restored after treatment with the demethylating agent in dose-dependent manner, implying that DNA methylation might be a mechanism involved in the RASSF1A inactivation in the selected cells (Fig. 2A, upper panel). Moreover, immunofluorescence study revealed that RASSF1A protein expression was restored by the demethyl- ating agent, mainly in the perinuclear area of the cancer cells (Fig. 2A, lower panel). Based on the results of the demethylating agent, the methylation status of the RASSF1A promoter was determined by MSP analysis before and after treatment of 3 different breast cancer cell lines with 5-aza-deoxycytidine, and the demethylating agent induced the appearance of unmethylated alleles of the RASSF1A (Fig. 2B). Therefore, the 
A
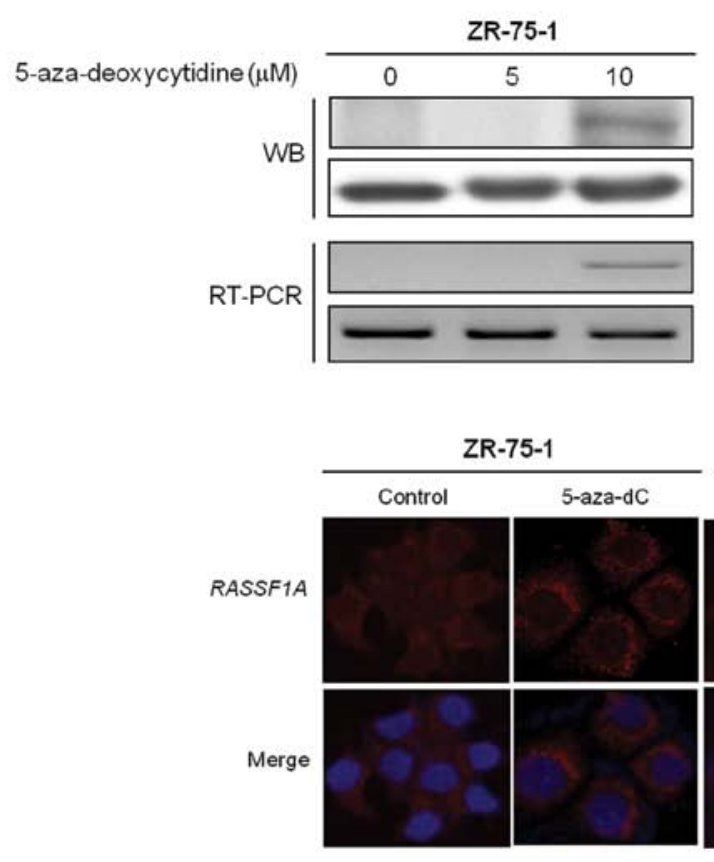
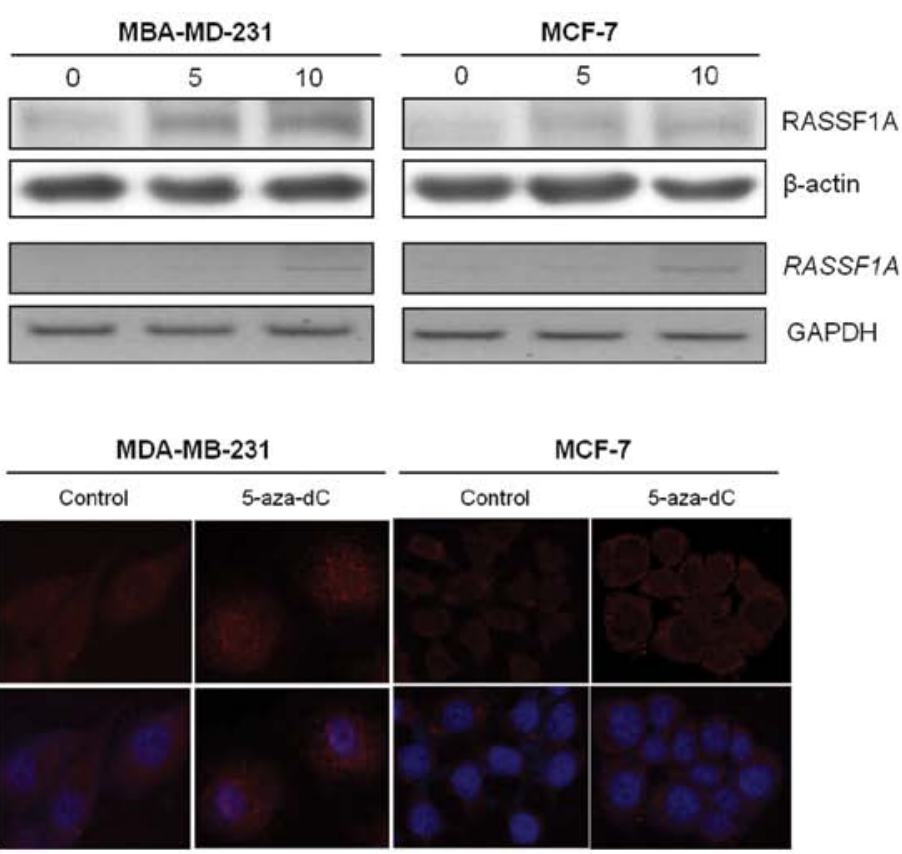

$\mathbf{B}$

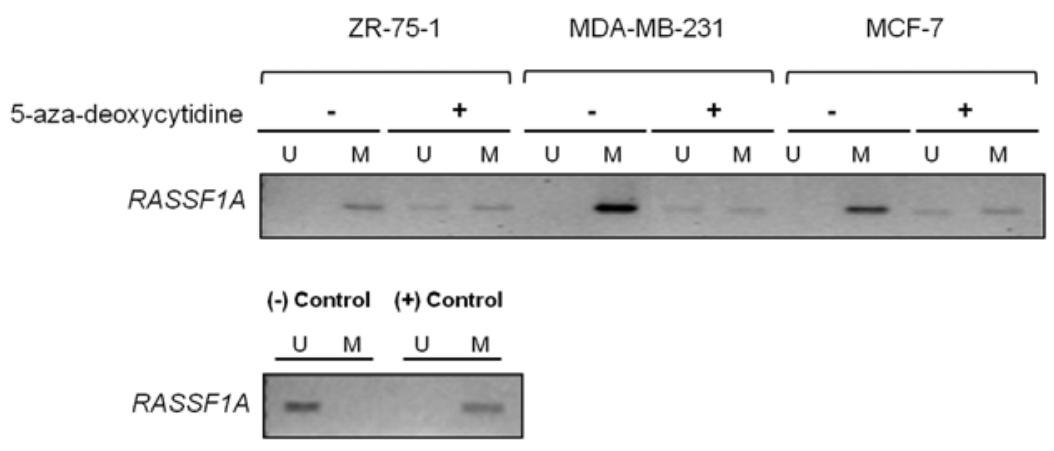

Figure 2. Suppression of RASSF1A by methylation in breast cancer. (A) Re-expression of RASSF1A by treatment of 3 different breast cancer cell lines with 5-azadeoxycytidine. Western blot analysis and RT-PCR show that RASSF1A is re-expressed by treatment with increasing concentrations of 5-azadeoxycytidine (upper panel). $\beta$-actin and GAPDH were used as internal controls. Immunofluorescence study confirms the re-expression of perinuclear RASSF1A (red) in breast cancer cells by 5 -azadeoxycytidine treatment (x400, lower panel). (B) MSP analysis before and after treatment of ZR 75-1, MDA-MB-231 and MCF-7 cells with 5-azadeoxycytidine. Bisulfite-converted universally methylated human DNA standard served as a positive control for methylation, and human lymphocyte DNA was included as an unmethylated RASSF1A. M, methylated alleles; $\mathrm{U}$, unmethylated alleles.

decreased RASSF1A gene expression was associated with the RASSF1A promoter methylation in breast cancer.

Quantitative analysis of RASSF1A methylation by pyrosequencing and relationship with clinicopathological characteristics of breast cancer patients. The associations between the promoter methylation status of RASSF1A and relevant demographic and clinicopathological characteristics are shown in Table I. The 7 CpG sites were analyzed by methylation-sensitive pyrosequencing and a representative pyrogram is shown in Fig. 3A. Pyrosequencing showed that the mean level of methylation in $7 \mathrm{CpG}$ sites in the 45 primary breast cancers ranged from $1.08 \%$ to $59.8 \%$, and 24 of 45 tumors $(53.3 \%)$ exhibited a high level of methylation (>20\%). Interestingly, triple negative tumors had significantly lower level of methylation in the promoter region of $R A S S F 1 A$ at $14.4 \pm 11.9 \%$ compared to non-triple negative tumors $(24.8 \pm 17.0 \%, \mathrm{p}=0.041$; Fig. 3B). Furthermore, it is of an interest to note that the mean level of methylation in RASSFIA was significantly higher in patients who did not respond to docetaxel-based chemotherapy $(30.6 \pm 8.5 \%)$ than patients with partial or complete response $(20.1 \pm 11.2 \%, p=0.042$; Fig. 3C). Mean level of methylation in $7 \mathrm{CpG}$ sites of the promoter region of RASSF1A in ER-positive tumors was significantly higher at $28.2 \pm 17.7 \%$ compared to ER-negative tumors $(17.0 \pm 14.4 \%, \mathrm{p}=0.024)$. Positive for PR showed the same pattern of association as observed in ER (positive: $29.5 \pm 17.4 \%$, negative: $17.9 \pm 15.1 \%, \mathrm{p}=0.026$ ). However, there was no significant correlation between RASSF1A protein expression and the level of promoter methylation or any clinicopathological characterisitics in primary breast cancers in this study (Table I).

Multivariate analysis showed that low level of methylation $(<20 \%)$ in RASSF1A was an independent predictor for response to chemotherapy after adjusted for ER (negative vs positive), PR (negative vs positive), HER-2 (negative vs positive), tumor grade (grade I/II vs III), p53 immunostaining (low; <20\% vs high; $\geq 20 \%$ ), and Ki-67 (low vs high) in these 45 patients $($ odds ratio $=15.99,95 \%$ confidence interval $=1.16-219.29$, 
A

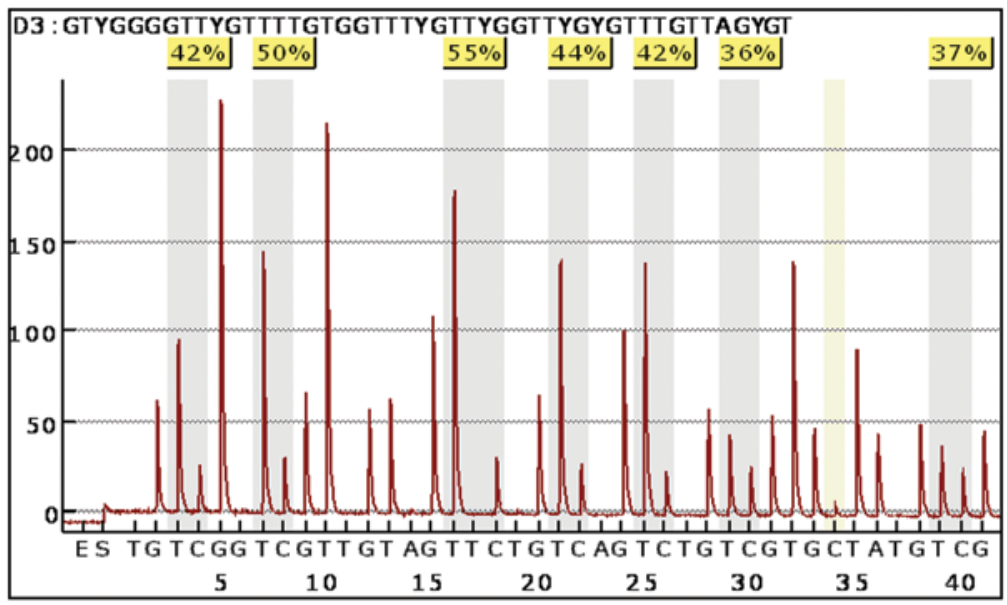

B

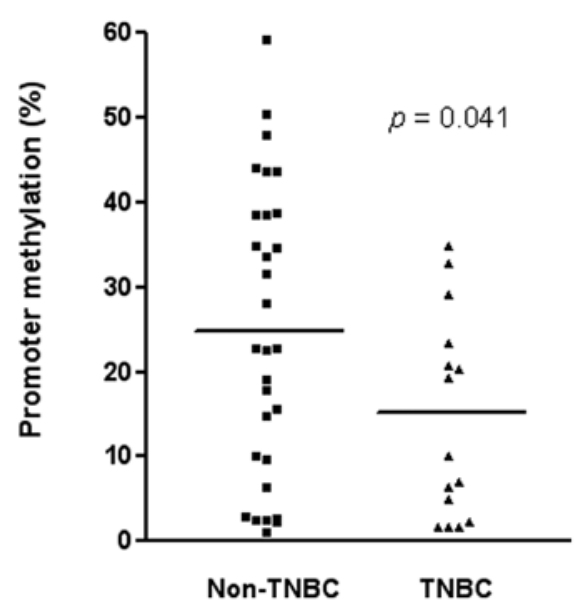

C

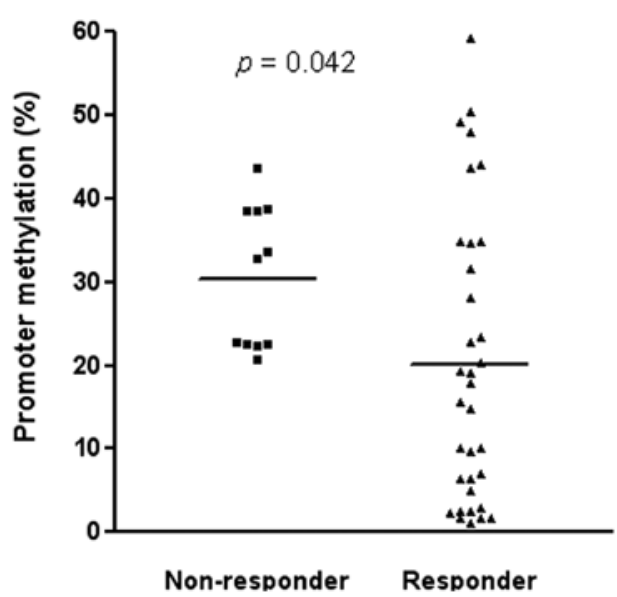

Figure 3. Quantitative analysis of RASSF1A methylation by pyrosequencing. (A) Pyrogram from quantification of methylation of 7 CpG sites at the RASSF1A promoter. During the pyrosequencing reaction, a ' $\mathrm{C}$ ' is incorporated if the template $\mathrm{CpG}$ is methylated, while a ' $\mathrm{T}$ ' is incorporated if the template $\mathrm{CpG}$ is unmethylated. In the resulting pyrogram, the proportion of C:T reflects the degree of methylation at the particular CpG sites assessed. (B) Comparison of mean level of methylation of RASSF1A between non-triple negative breast cancer (TNBC) and TNBC patients. Bar indicates mean level of methylation of RASSF1A in each group. P denotes significance of t-test. (C) Comparison of mean level of methylation of RASSF1A between non-responder and responder to chemotherapy. Bar indicates mean level of methylation of RASSF1A in each group.

Table II. Multivariate logistic regression model for response to chemotherapy.

Factor

Response to chemotherapy

\section{OR $(95 \% \mathrm{CI})$}

0.00

$8.970 \mathrm{E} 8$

$4.31(.53-34.96)$

$0.61(.016-23.35)$

$49.02(1.46-1639.25)$

$0.17(.004-7.06)$

15.99 (1.16-219.29)
$\mathrm{P}$

0.99

0.99

0.17

0.79

0.03

0.35

0.03

RASSF 1A methylation (low vs high)

OR, odds ratio; CI, confidence interval; ER, estrogen receptor; PR, progesterone receptor; HER-2, human epidermal growth factor receptor 2.

p=0.03; Table II). Patients with low level of p53 immunostaining $(<20 \%)$ were also more sensitive to docetaxel-based chemotherapy than the patients with tumors of high level of p53 immunostaining.
RASSF1A modulates docetaxel-induced cell death. Since the docetaxel-based chemotherapy seemed less effective in patients with methylated promoter region of RASSF1A, we examined potential interaction between $R A S S F 1 A$ and 
A

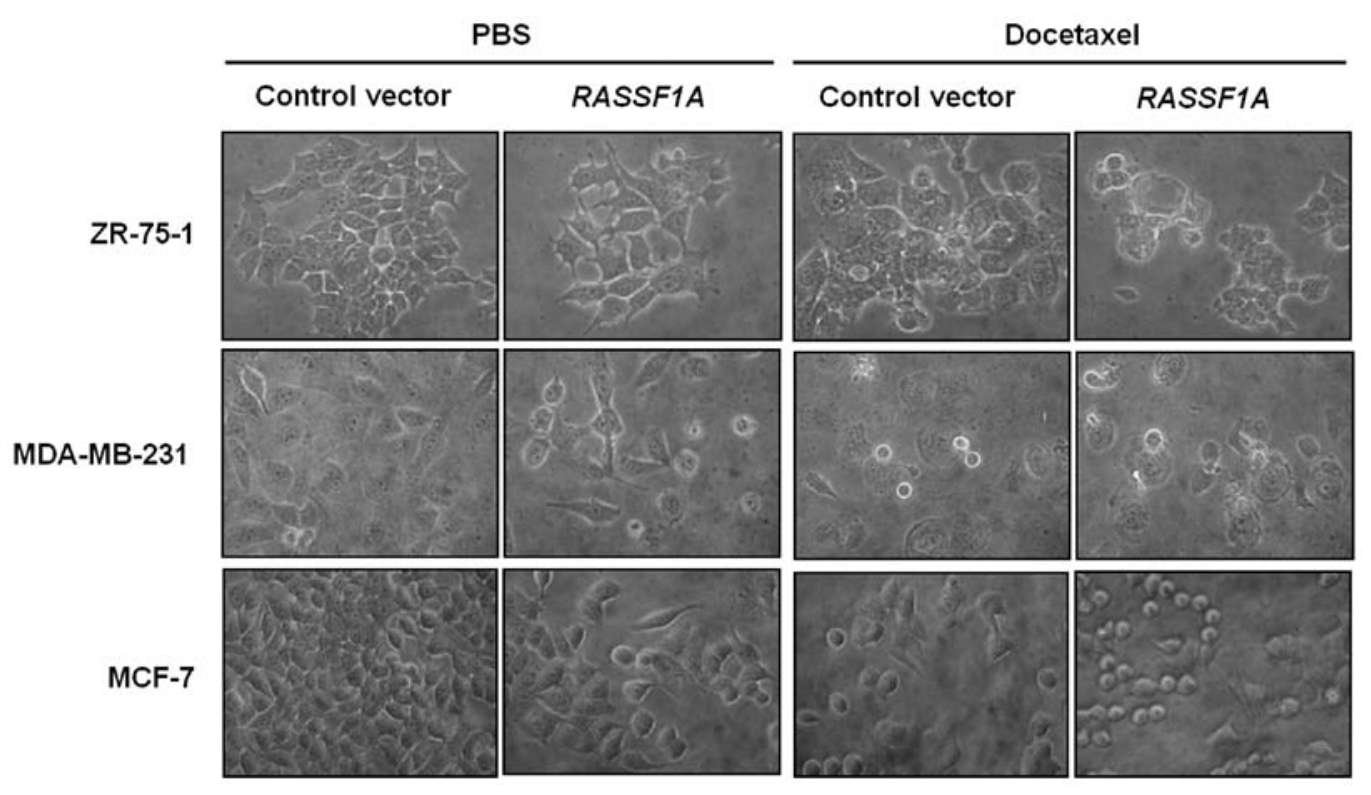

B
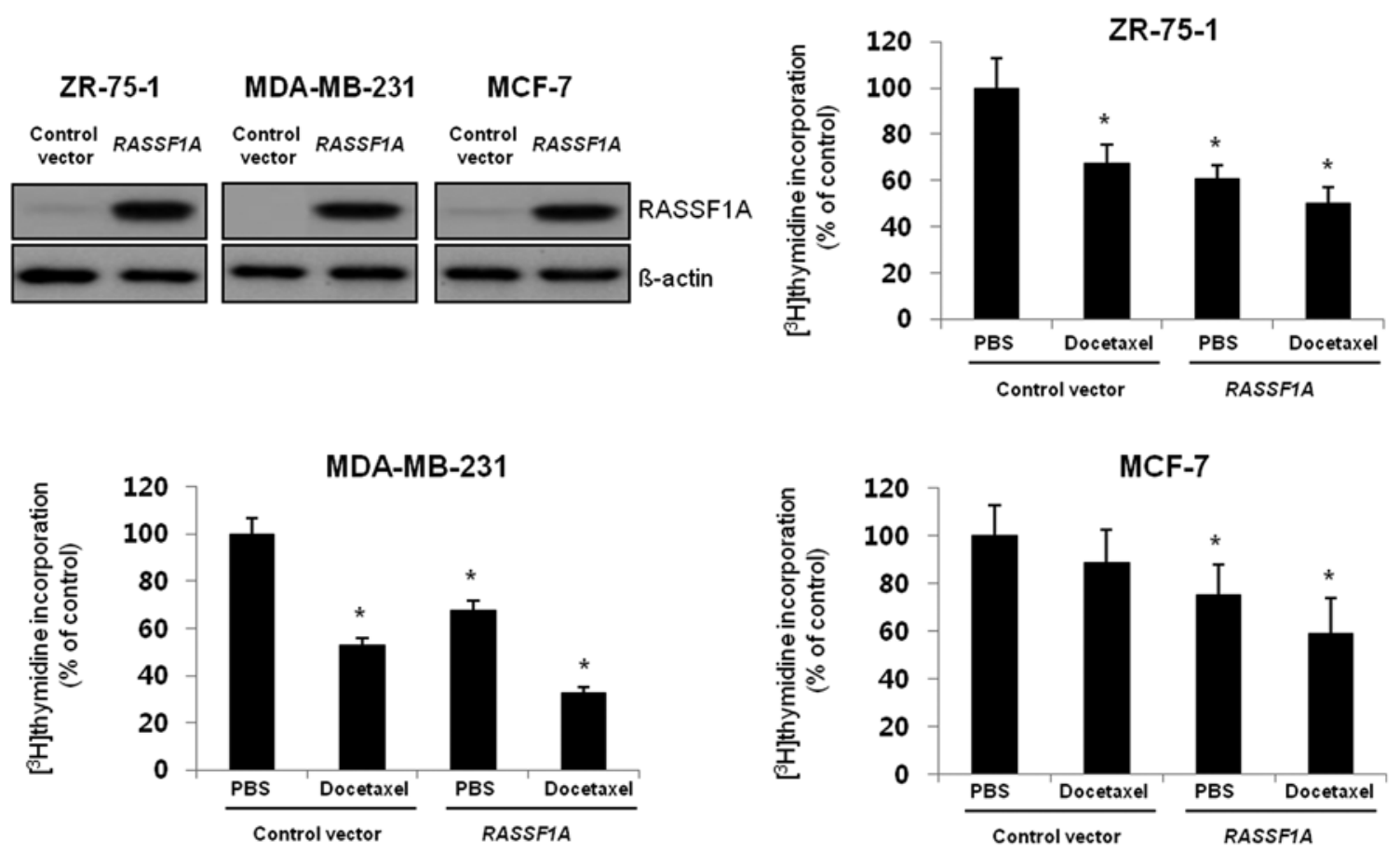

Figure 4. RASSF1A modulates growth inhibitory effect of docetaxel. (A) The effect of RASSF1A on docetaxel-induced cell growth inhibition in 3 breast cancer cell lines was analyzed by phase contrast light microscopy. Control vector indicates pcDNA3.1. (B) Upper right panel, expression status of RASSF1A in RASSF1A and control vector stably transfected cells. Upper left and low panel, $\left[{ }^{3} \mathrm{H}\right]$-thymidine incorporation assay in each stably transfected breast cancer cell line. Statistical analysis was performed on the basis of PBS-treated, control vector transfected cells in each cell type. ${ }^{*} \mathrm{p}<0.05$.

docetaxel. Therefore, we transfected RASSF1A or control vector to the breast cancer cells (ZR-75-1, MDA-MB-231, MCF-7), and investigated whether reintroduction of RASSF1A had any growth inhibitory effect on breast cancer cells. As shown in Fig. 4A, the number of round-shape cells which are typical features of apoptotic cells was increased in RASSF1A transfected cells compared with the control vector-transfected cells and the effect was greatly enhanced after treatment of docetaxel. Next, the cooperative effect was confirmed in a proliferation assay showing that docetaxel induced a marked reduction of $\left[{ }^{3} \mathrm{H}\right]$-thymidine incorporation in the cells stably transfected with RASSF1A, compared with the control vector-transfected cells (Fig. 4B). Therefore, these results indicate that the antiproliferative effect of docetaxel was enhanced in the presence of RASSF1A in breast cancer cells.

RASSF1A enhances docetaxel-induced cell cycle arrest. The cooperative effects of RASSFIA and docetaxel in the cell survival and proliferation prompted us to investigate whether reintroduction of $R A S S F 1 A$, in addition to docetaxel, has any impact on the cell cycle progression. When the RASSF1A-transfected breast cancer cells were treated with docetaxel for $24 \mathrm{~h}$, they showed statistically significant increase of $\mathrm{G} 2 / \mathrm{M}$ phase cell population, compared to those of empty 
A
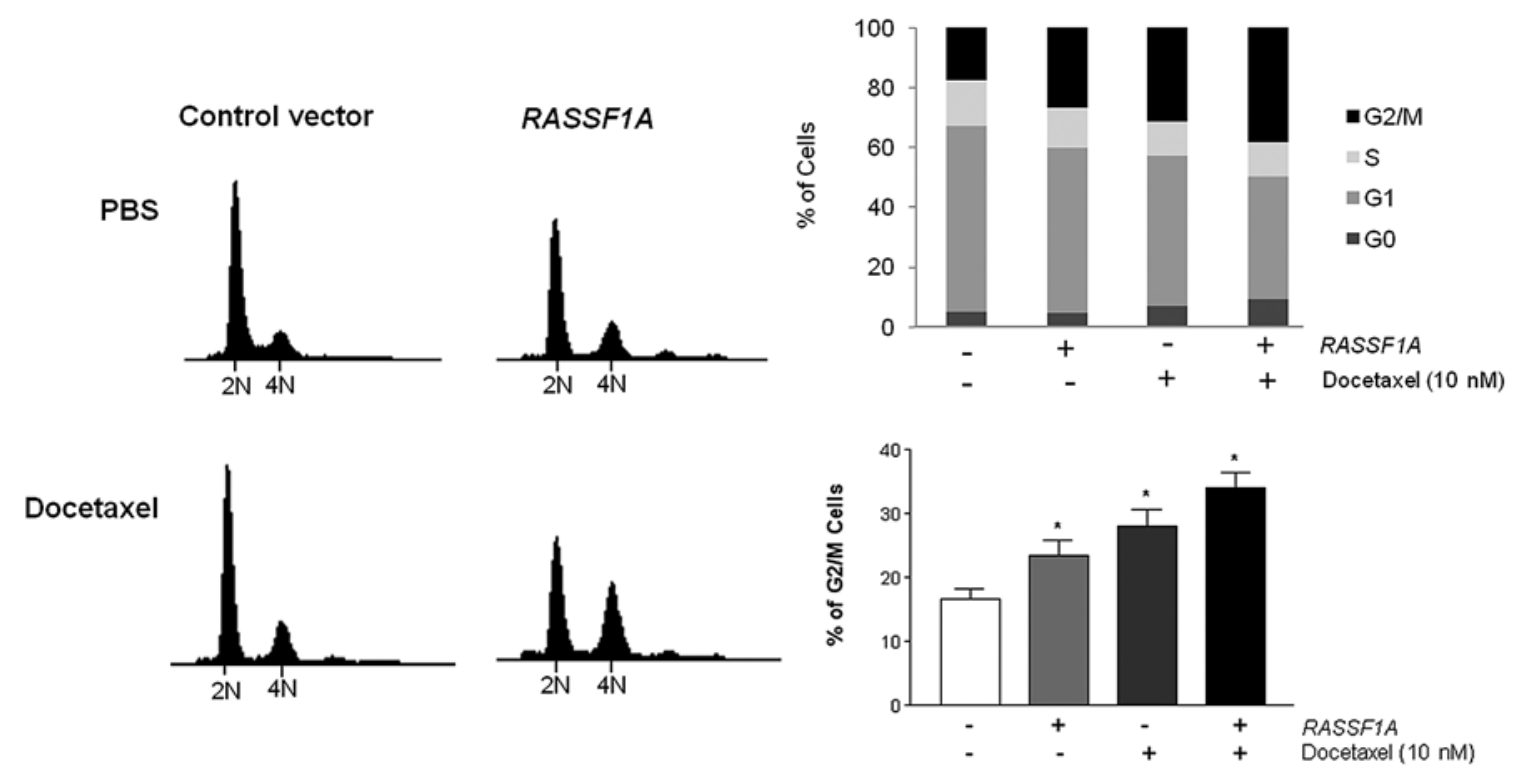

B
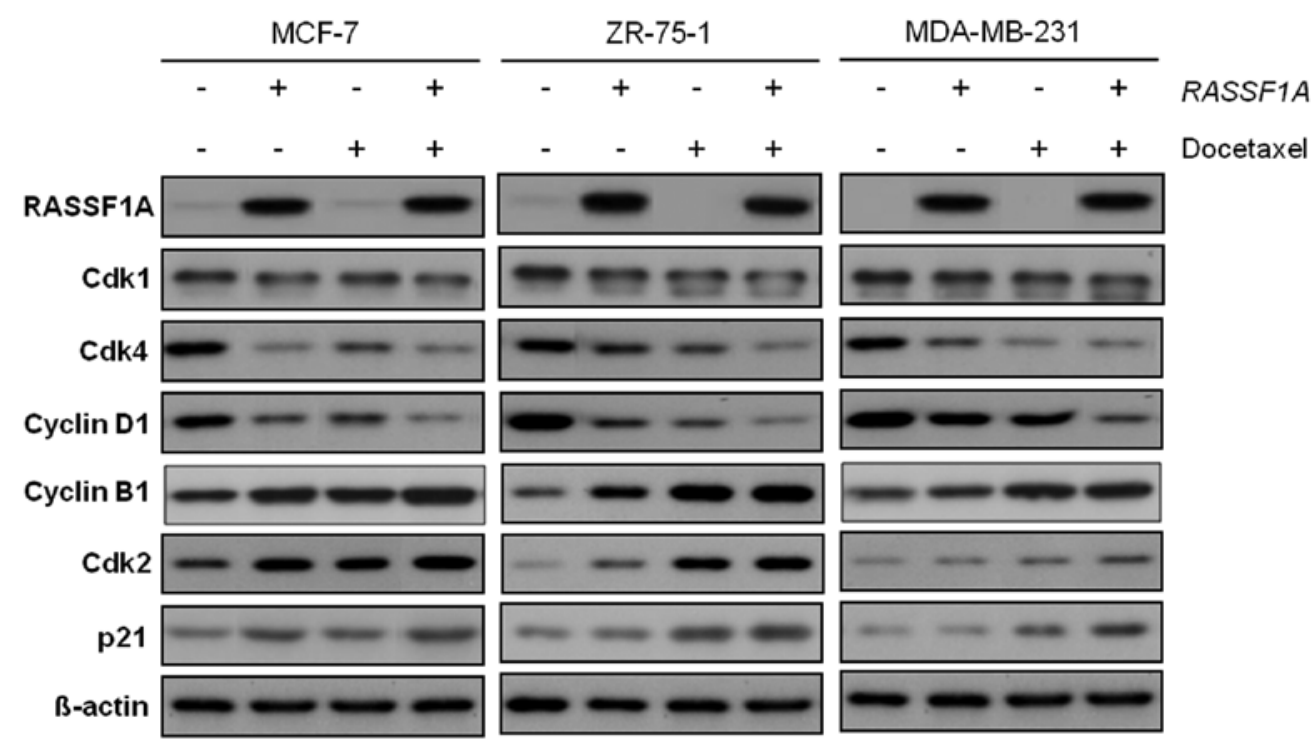

Figure 5. RASSF1A enhances docetaxel-induced cell cycle arrest. (A) The effect of RASSF1A on docetaxel-induced cell cycle arrest was evaluated in MDA-MB231 cells stably transfected with RASSF1A or control vector. Cells were analyzed for cell cycle progression. Positions of cell populations with $2 \mathrm{~N}$ and $4 \mathrm{~N}$ DNA content are indicated (upper panel). Histogram plotting of the cell cycle progression is shown in lower left, while comparison of cells in G2/M phase is shown in lower right. Columns, means ( $\mathrm{n}=3)$; bars, $\mathrm{SEM}$; $\mathrm{p}<0.05$. Expression of cell cycle regulating proteins is shown by western blot analysis. Three breast cancer cell lines transfected with RASSF1A and control vector were analyzed with or without exposure to docetaxel $(10 \mathrm{nM})$.

vector transfected cells ( $\mathrm{p}=0.02$, Fig. $5 \mathrm{~A})$. The result indicates that the cooperative effect of RASSFIA and docetaxel is accompanied with cell cycle arrest at the G2/M phase. Further analysis using western blot analysis showed that the cell cycle arrest at the G2/M phase in the breast cancer cells was associated with the induction of cyclin B1, Cdk2 and $\mathrm{p} 21$ by both RASSF1A and docetaxel (Fig. 5B). Maximum cyclin B1, Cdk2 and $\mathrm{p} 21$ induction was observed when docetaxel was applied to the RASSF1A-transfected breast cancer cells, whereas Cdk1, $\mathrm{Cdk} 4$, and cyclin D1 were greatly decreased when breast cancer cells reintroduced with $R A S S F 1 A$ were treated with docetaxel. These findings indicate that the effects of RASSF $1 A$ and docetaxel on the $\mathrm{G} 2 / \mathrm{M}$ phase cell cycle arrest are associated with accumulation of cyclin B1/Cdk2/p21 and suppression of Cdk1, Cdk4, and cyclin D1 in breast cancer cells.

\section{Discussion}

RASSF1A has been reported to be frequently silenced in many cancer types including breast cancer; however, the biologic relevance in clinical standpoint has not yet been clearly characterized. Because there is a probability that unsatisfactory response in breast cancer treatment may in part be due to silencing of gene, the role and clinical relevance of a frequently silenced tumor suppressor gene, RASSF1A, was examined in this study. In the current study, we found that the promoter region of RASSF1A was frequently methylated in the primary breast cancer samples from 45 locally advanced or metastatic cancer patients, in good agreement with previous reports. In addition, we showed that level of methylation of RASSF1A was independent factor for response to docetaxel-based chemotherapy in 
this study. Moreover, RASSF1A enhanced docetaxel-mediated growth inhibition by inducing cell cycle arrest and altering the level of related proteins. Our results demonstrated that methylation status of RASSF1A modulates the efficacy of docetaxel chemotherapy and regulates docetaxel mediated cell cycle arrest in breast cancers.

There are a few studies suggesting the methylated RASSFIA as a potential biomarker for poor prognosis in breast cancer (12-14). However, no biologically relevant mechanism, thus far, has been presented. In this context, we showed herein that the methylation status of $R A S S F 1 A$ was significantly associated with response to docetaxel-based chemotherapy: cell line studies showed that RASSF1A per se had docetaxel-like effect in suppressing growth and proliferation of breast cancer cells via inducing cell cycle arrest. Furthermore, cooperative activity of RASSF1A in docetaxel-induced cell cycle arrest could be a potential mechanism for differential response among breast cancer patients.

Docetaxel is one of the prototype taxane and a front line chemotherapeutic agent in the treatment of breast, ovary, lung, and head and neck cancers. Despite of its widespread use and success in clinical practice, there are significant shortcomings including myelosuppression, peripheral neuropathy, and primary or secondary resistance (30). Nevertheless, there is no rational biomarker for the identification of patients who are most likely to respond to docetaxel. Of the predictive markers for the response to neoadjuvant chemotherapy, biology-based tumor types have been shown to be most consistent and reproducible among the studies (4). However, it is still unsatisfactory marker due to strong heterogeneity within the subgroups. More mechanistic markers such as Ki-67 (31) and topoisomerase II $\alpha$ (32) have also been suggested as valuable predictive markers for response to anthracyclines and other chemotherapeutics. For the taxanes, however, no biologic marker has been suggested for the prediction of response based on mechanistic study. In the present study, we found a significant association between the methylation level of RASSF1A and response to docetaxel-based chemotherapy in patients with locally advanced or recurrent breast cancer. Additional multivariate analysis showed that low level of methylation $(<20 \%)$ in the promoter region of $R A S S F 1 A$ was an independent factor for response to docetaxel-based chemotherapy after adjusted for ER, PR, HER-2, p53 immunoreactivity, and Ki-67 staining. Furthermore, the specific modulating effect of RASSF1A on docetaxel-induced cytotoxicity was demonstrated in the cell culture system. Therefore, the loss of RASSF1A for the prediction of docetaxel-based chemotherapy also seems to deserve further investigation.

It is now well known that taxanes exert their anti-cancer effect by inducing mitotic arrest of cancer cells. When cells are exposed to anti-mitotics, they are arrested in mitosis and then undergo one of several fates; death in mitosis, unequal division, or exit without division (33). However, little is known about how cells respond to this prolonged cell cycle delay. Recent studies suggested that commitment to mitotic exit is determined by the level of cyclin B1 in anti-mitotics exposed cells (34). Therefore, it seems important to define the factors that govern the degradation of cyclin B1 during a prolonged mitotic arrest. Notably, our present results showed that overexpression of RASSF1A in breast cancers induced the accumulation of cyclin B1, as observed in docetaxel-treated cells in consistent with previous studies $(21,35)$. Furthermore, the accumulation of cyclin B1 in the RASSF1A-transfected cells was significantly enhanced by docetaxel. Thus, RASSF1A could be considered as one of the factors controlling degradation of cyclin B1 during the mitotic arrest which was induced by docetaxel in breast cancer cells. In the present study, the accumulation of p21 and decreased levels of Cdk 1, Cdk 4, and cyclin D1 were also found to be involved in the induction of cell cycle arrest and apoptosis by both docetaxel and RASSF1A. In addition, decreased expression of Cdk 1 by RASSF1A might also contribute to cell death after mitotic exit, since Cdk 1 has been shown to inhibit caspase-9 (36). Our present observations therefore show that RASSF1A might be an important biologic contributor to docetaxel-induced cell cycle arrest and, finally, cell death in breast cancer cells.

In conclusion, the data presented herein led us to propose that hypermethylated RASSF1A might be an important modulating factor for efficacy of docetaxel-based chemotherapy in breast cancers. We also provided mechanistic data that the tumor suppressor, $R A S S F 1 A$, has a cooperative effect along with docetaxel in inducing cell cycle arrest in breast cancer. Our results are expected to contribute to the identification of biomarkers in predicting the response of breast cancer patients to docetaxel. Since our data are limited by the small sample size and locally advanced stage cancers in most of the cases, the statistical significances shown here are still marginal. Therefore, further research with a large number of clinical samples is needed to confirm our results.

\section{Acknowledgements}

This study was supported by a grant of the Korea Healthcare technology R\&D Project, Ministry for Health, Welfare \& Family Affairs, Republic of Korea (A084400). Tissue samples were provided by the Korean Lung Tissue Bank through the Infrastructure Project for Basic Science of the Ministry of Education, Science and Technology, Korea.

\section{References}

1. Jung KW, Park S, Kong HJ, et al: Cancer statistics in Korea: incidence, mortality, survival, and prevalence in 2008. Cancer Res Treat 43: 1-11, 2011.

2. Rastogi P, Anderson SJ, Bear HD, et al: Preoperative chemotherapy: updates of National Surgical Adjuvant Breast and Bowel Project Protocols B-18 and B-27. J Clin Oncol 26: 778-785, 2008.

3. Mauri D, Pavlidis N and Ioannidis JP: Neoadjuvant versus adjuvant systemic treatment in breast cancer: a meta-analysis. $\mathbf{J}$ Natl Cancer Inst 97: 188-194, 2005.

4. Darb-Esfahani S, Loibl S, Muller BM, et al: Identification of biology-based breast cancer types with distinct predictive and prognostic features: role of steroid hormone and HER 2 receptor expression in patients treated with neoadjuvant anthracycline/ taxane-based chemotherapy. Breast Cancer Res 11: R69, 2009.

5. Chang HR, Glaspy J, Allison MA, et al: Differential response of triple-negative breast cancer to a docetaxel and carboplatinbased neoadjuvant treatment. Cancer 116: 4227-4237, 2010.

6. Christensen BC, Kelsey KT, Zheng S, et al: Breast cancer DNA methylation profiles are associated with tumor size and alcohol and folate intake. PLoS Genet 6: e1001043, 2010.

7. Yan PS, Shi H, Rahmatpanah F, et al: Differential distribution of DNA methylation within the RASSF1A CpG island in breast cancer. Cancer Res 63: 6178-6186, 2003.

8. Yeo W, Wong WL, Wong N, Law BK, Tse GM and Zhong S: High frequency of promoter hypermethylation of RASSF1A in tumorous and non-tumourous tissue of breast cancer. Pathology 37: 125-130, 2005. 
9. Honorio S, Agathanggelou A, Schuermann M, et al: Detection of RASSF1A aberrant promoter hypermethylation in sputum from chronic smokers and ductal carcinoma in situ from breast cancer patients. Oncogene 22: 147-150, 2003.

10. Shukla S, Mirza S, Sharma G, Parshad R, Gupta SD and Ralhan R: Detection of RASSF1A and RARbeta hypermethylation in serum DNA from breast cancer patients. Epigenetics 1: 88-93, 2006.

11. Yazici H, Terry MB, Cho YH, et al: Aberrant methylation of RASSF1A in plasma DNA before breast cancer diagnosis in the Breast Cancer Family Registry. Cancer Epidemiol Biomarkers Prev 18: 2723-2725, 2009.

12. Kioulafa M, Kaklamanis L, Mavroudis D, Georgoulias V and Lianidou ES: Prognostic significance of RASSF1A promoter methylation in operable breast cancer. Clin Biochem 42 : 970-975, 2009.

13. Karray-Chouayekh S, Trifa F, Khabir A, et al: Aberrant methylation of RASSF1A is associated with poor survival in Tunisian breast cancer patients. J Cancer Res Clin Oncol 136: 203-210, 2010.

14. Martins AT, Monteiro P, Ramalho-Carvalho J, et al: High RASSF1A promoter methylation levels are predictive of poor prognosis in fine-needle aspirate washings of breast cancer lesions. Breast Cancer Res Treat 129: 1-9, 2011.

15. Kim DH, Kim JS, Ji YI, et al: Hypermethylation of RASSF1A promoter is associated with the age at starting smoking and a poor prognosis in primary non-small cell lung cancer. Cancer Res 63: 3743-3746, 2003.

16. Wang J, Lee JJ, Wang L, et al: Value of p16INK4a and RASSF1A promoter hypermethylation in prognosis of patients with resectable non-small cell lung cancer. Clin Cancer Res 10: 6119-6125, 2004.

17. Seidel C, Bartel F, Rastetter M, et al: Alterations of cancerrelated genes in soft tissue sarcomas: hypermethylation of RASSF1A is frequently detected in leiomyosarcoma and associated with poor prognosis in sarcoma. Int $\mathrm{J}$ Cancer 114: 442-447, 2005

18. Fischer JR, Ohnmacht U, Rieger N, et al: Promoter methylation of RASSF1A, RARbeta and DAPK predict poor prognosis of patients with malignant mesothelioma. Lung Cancer 54: 109-116, 2006

19. Ahmed-Choudhury J, Agathanggelou A, Fenton SL, et al: Transcriptional regulation of cyclin A2 by RASSF1A through the enhanced binding of $\mathrm{p} 120 \mathrm{E} 4 \mathrm{~F}$ to the cyclin A2 promoter. Cancer Res 65: 2690-2697, 2005

20. Donninger H, Vos MD and Clark GJ: The RASSF1A tumor suppressor. J Cell Sci 120: 3163-3172, 2007.

21. Song MS, Song SJ, Ayad NG, et al: The tumour suppressor RASSF1A regulates mitosis by inhibiting the APC-Cdc20 complex. Nat Cell Biol 6: 129-137, 2004.
22. Liu L, Tommasi S, Lee DH, Dammann R and Pfeifer GP: Control of microtubule stability by the RASSF1A tumor suppressor. Oncogene 22: 8125-8136, 2003.

23. Whang YM, Park KH, Jung HY, Jo UH and Kim YH Microtubule-damaging agents enhance RASSF1A-induced cell death in lung cancer cell lines. Cancer 115: 1253-1266, 2009.

24. Reu FJ, Bae SI, Cherkassky L, et al: Overcoming resistance to interferon-induced apoptosis of renal carcinoma and melanoma cells by DNA demethylation. J Clin Oncol 24: 3771-3779, 2006.

25. Reu FJ, Leaman DW, Maitra RR, et al: Expression of RASSF1A, an epigenetically silenced tumor suppressor, overcomes resistance to apoptosis induction by interferons. Cancer Res 66: 2785-2793, 2006.

26. Eisenhauer EA, Therasse P, Bogaerts J, et al: New response evaluation criteria in solid tumours: revised RECIST guideline (version 1.1). Eur J Cancer 45: 228-247, 2009.

27. Pallares J, Velasco A, Eritja N, et al: Promoter hypermethylation and reduced expression of RASSF1A are frequent molecular alterations of endometrial carcinoma. Mod Pathol 21: 691-699, 2008.

28. Ateeq B, Unterberger A, Szyf M and Rabbani SA: Pharmacological inhibition of DNA methylation induces proinvasive and prometastatic genes in vitro and in vivo. Neoplasia 10 : 266-278, 2008

29. Liu Z, Wu J, Xie Z, et al: Quantification of regional DNA methylation by liquid chromatography/tandem mass spectrometry. Anal Biochem 391: 106-113, 2009.

30. McGrogan BT, Gilmartin B, Carney DN and McCann A: Taxanes, microtubules and chemoresistant breast cancer. Biochim Biophys Acta 1785: 96-132, 2008.

31. Caudle AS, Gonzalez-Angulo AM, Hunt KK, et al: Predictors of tumor progression during neoadjuvant chemotherapy in breast cancer. J Clin Oncol 28: 1821-1828, 2010.

32. Coon JS, Marcus E, Gupta-Burt S, et al: Amplification and overexpression of topoisomerase IIalpha predict response to anthracycline-based therapy in locally advanced breast cancer. Clin Cancer Res 8: 1061-1067, 2002.

33. Gascoigne KE and Taylor SS: How do anti-mitotic drugs kill cancer cells? J Cell Sci 122: 2579-2585, 2009.

34. Gascoigne KE and Taylor SS: Cancer cells display profound intra- and interline variation following prolonged exposure to antimitotic drugs. Cancer Cell 14: 111-122, 2008.

35. Whang YM, Kim YH, Kim JS and Yoo YD: RASSF1A suppresses the c-Jun-NH2-kinase pathway and inhibits cell cycle progression. Cancer Res 65: 3682-3690, 2005.

36. Allan LA and Clarke PR: Phosphorylation of caspase-9 by CDK1/cyclin B1 protects mitotic cells against apoptosis. Mol Cell 26: 301-310, 2007. 